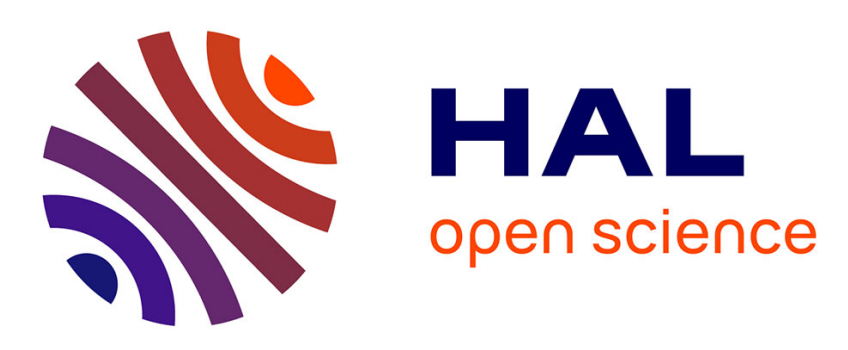

\title{
Six-Port Reflectometer in WR15 Metallic Waveguide for Free-Space Sensing Applications
}

\author{
Kamel Haddadi, Christophe Loyez, Laurent Clavier, Denis Pomorski, Simon
} Lallemand

\section{- To cite this version:}

Kamel Haddadi, Christophe Loyez, Laurent Clavier, Denis Pomorski, Simon Lallemand. Six-Port Reflectometer in WR15 Metallic Waveguide for Free-Space Sensing Applications. 2018 IEEE Topical Conference on Wireless Sensors and Sensor Networks (WiSNet 2018), Jan 2018, Anaheim, United States. hal-02013933

\section{HAL Id: hal-02013933 https://hal.science/hal-02013933}

Submitted on 11 Feb 2019

HAL is a multi-disciplinary open access archive for the deposit and dissemination of scientific research documents, whether they are published or not. The documents may come from teaching and research institutions in France or abroad, or from public or private research centers.
L'archive ouverte pluridisciplinaire HAL, est destinée au dépôt et à la diffusion de documents scientifiques de niveau recherche, publiés ou non, émanant des établissements d'enseignement et de recherche français ou étrangers, des laboratoires publics ou privés. 


\title{
Six-Port Reflectometer in WR15 Metallic Waveguide for Free-Space Sensing Applications
}

\author{
${ }^{1}$ Kamel Haddadi, ${ }^{1}$ Christophe Loyez, ${ }^{1}$ Laurent Clavier, ${ }^{2}$ Denis Pomorski and ${ }^{3}$ Simon Lallemand \\ ${ }^{1}$ Univ. Lille, CNRS, UMR 8520 - IEMN, F-59000 Lille, France \\ ${ }^{2}$ Univ. Lille, CNRS, UMR 9189 - CRIStAL, F-59000 Lille, France \\ ${ }^{3}$ Groupe Segula Technologies, Valenciennes, France \\ kamel.haddadi@iemn.univ-lille1.fr
}

\begin{abstract}
This work describes the design, fabrication and measurements of a six-port reflectometer in metallic waveguide technology for operation around $60 \mathrm{GHz}$. The system integration is based on WR15 building blocks. An insitu linearization of the detectors associated to a vector calibration procedure is provided to determine the calibrated IQ components from the measured voltages. Near-field freespace distance measurements from contact to stand-off distance of two free-space wavelengths are shown to validate the technique proposed.
\end{abstract}

Index Terms - Six-port, reflectometer, IQ demodulation, millimeter-wave, distance measurement,

\section{INTRODUCTION}

The six-port technique has been introduced in the 1970 s as a simple technique for measuring power and reflection coefficient in the microwave regime [1]. Since then, a variety of six-port systems have been exemplary demonstrated in metallic guide, substrate integrated waveguide (SIW), planar and monolithic forms [2]-[8]. Each technology presents own advantages and drawbacks in terms of circuit size, power consumption, immunity to temperature/hygrometry variations, fabrication facility, system integration, measurement performance and cost [8]. Therefore, the choice of the technology is mainly driven by the requirements of the targeted application.

This work presents a fully WR15 metallic waveguide six-port reflectometer operating at $60 \mathrm{GHz}$ for near-field sensing applications, i.e. near-field high precision distance measurement. Unlike planar technologies systems, waveguides are highly shielded to provide isolation between nearby signals. As they rely on air as a dielectric, the technology reduces the need for consistency in the dielectric material and presents better immunity to environmental variations. Furthermore, the building blocks of the six-port circuit can be easily connected each other as they are inherently matched. As the size is directly related to the operation wavelength, millimeterwave frequency operation is preferred to reduce the circuit size.

\section{SIX-PORT IQ DEMODULATOR}

This section describes the design, fabrication and test of the six-port IQ demodulator. The proposed architecture and picture of the fabricated system are given in Fig. 1.

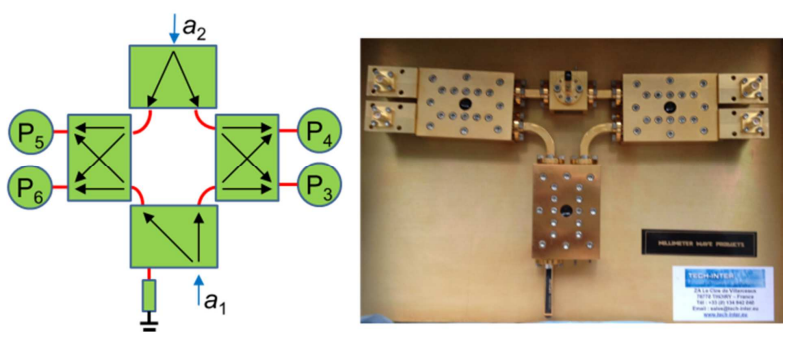

Fig. 1. (a) Structure of the six-port IQ demodulator. (b) Photograph of the WR15 waveguide six-port IQ demodulator.

The circuit is implemented using three $90^{\circ}$ hybrids with $20 \mathrm{~dB}$ isolation and $6 \%$ bandwidth around $60 \mathrm{GHz}$, a four port hybrid tee with one arm connected to a match termination for basic power splitting and four power detectors with typical video sensitivity of $500 \mathrm{mV} / \mathrm{mW}$ and tangential sensitivity of $-50 \mathrm{dBm}$. Interconnecting bends and twists are used for system integration. The reference millimeter-wave signal $a_{1}$ [fig. 1(a)] can be provided by a miniature high stability phase-locked source Mi-WAVE ${ }^{\mathrm{TM}} 957\left(P_{\mathrm{LO}}=11 \mathrm{dBm}\right)$ or a frequency synthetizer Keysight ${ }^{\mathrm{TM}}$ E8257D.

The first step concerns the linearization of the electrical response of the power detectors to correct deviation from quadratic response. For this experiment, the RF port (signal $a_{2}$ ) of the six-port demodulator is connected to a match termination to make the electrical response depending only of the LO source signal $a_{1}$. We present in Fig. 2 the detected voltages $V_{1}$ to $V_{4}$ measured for a source power varying from $10 \mu \mathrm{W}$ to $10 \mathrm{~mW}$ at $60 \mathrm{GHz}$. 

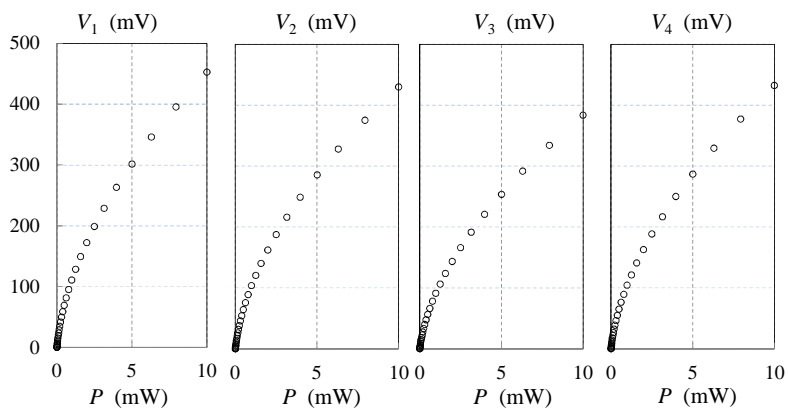

Fig. 2. Detected voltages as a function of the input millimeter-wave LO power $-\mathrm{F}=60 \mathrm{GHz}$.

From Fig. 2, the linearity is degraded by distorsions. The linearization procedure consists to interpolate the measured data using a polynomial function. In this study, a $5^{\text {th }}$ order polynomial is used. As an example, the interpolation model for the voltage $V_{1}$ is given by

$P_{1}(\mathrm{~mW})=-1.43 \times 10^{-13} V_{1}^{5}+1.66 \times 10^{-10} V_{1}^{4}-8.04 \times 10^{-8} \mathrm{~V}_{1}^{3}$ $+5.98 \times 10^{-5} V_{1}^{2}+4.02 \times 10^{-3} V_{1}+1.36 \times 10^{-2}$.

The next step consists of verifying the performance in mixing mode. In this configuration, the millimeter-wave signal $a_{2}$ with amplitude $\mathrm{A}_{\mathrm{RF}}$ is combined with the signal $a_{1}$ with amplitude $\mathrm{A}_{\mathrm{LO}}$. The theoretical powers $P_{3}$ to $P_{6}$ are given by

$$
\begin{aligned}
& P_{3}=\left|0.5\left(a_{2}+a_{1}\right)\right|^{2} \\
& P_{4}=\left|0.5\left(a_{2}-j a_{1}\right)\right|^{2} \\
& P_{5}=\left|0.5\left(a_{2}-a_{1}\right)\right|^{2} \\
& P_{6}=\left|0.5\left(a_{2}+j a_{1}\right)\right|^{2}
\end{aligned}
$$

The $60 \mathrm{GHz}$ LO and RF input signals are both obtained by the synthesizer using a power splitter. The source power is set to $11 \mathrm{dBm}$. The RF signal amplitude $A_{\mathrm{RF}}$ and relative phase-shift $\Delta \Phi$ are respectively adjusted with precise WR15 waveguide variable attenuator (MI-WAVE $510 \mathrm{~V} / 385$ ) and phase-shifter (MI-WAVE 528V/385) as shown in Fig. 3. The IQ components are defined as

$$
\begin{aligned}
& I=A_{\mathrm{RF}} \cos (\Delta \Phi) \sim P_{3}-P_{5} \\
& Q=A_{\mathrm{RF}} \sin (\Delta \Phi) \sim P_{6}-P_{4}
\end{aligned}
$$

A spatial (related to the spatial phase-shift $\Delta \Phi$ ) Fourier analysis is considered to correct the general forms given by (5) and (6) into the models (7) and (8) that encompasses mismatching and non-linear effects [9].

$$
\begin{aligned}
P_{3}-P_{5}= & y_{0}+y_{1} I+y_{2} Q+y_{3} I^{2}+y_{4} Q^{2}+y_{5}\left(I^{2}-3 I Q^{2}\right)+ \\
& y_{5}\left(Q^{2}-3 I^{2} Q\right) \\
P_{6}-P_{4}= & y_{0}^{\prime}+y_{1}^{\prime} I+y_{2}^{\prime} Q+y_{3}^{\prime} I^{2}+y_{4}^{\prime} Q^{2}+y_{5}^{\prime}\left(I^{2}-3 I Q^{2}\right)+ \\
& y_{6}^{\prime}\left(Q^{2}-3 I^{2} Q\right)
\end{aligned}
$$

These equations rely the powers to polynomial combinations of $I$ and $Q$ through eight real calibration constants $y_{i}$ and $y_{i}^{\prime}$. More information about the model construction is given in [9].

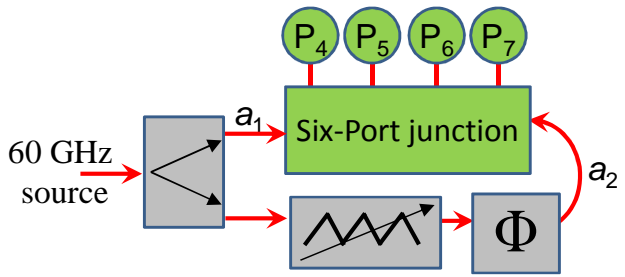

(a)

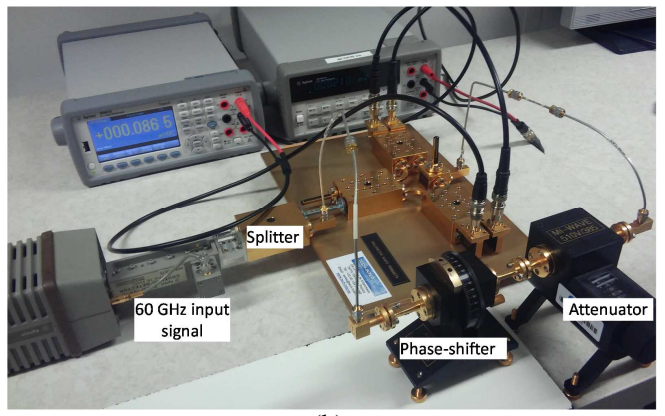

(b)

Fig. 3. Experimental test bench arrangement for IQ measurements.

The calibration coefficients $y_{i}$ and $y_{i}^{\prime}$ are determined by fitting the measured powers to the models (7) and (8). For comparison purposes, the calibration constants are determined for the $1^{\text {st }}\left(y_{3}=y_{4}\right.$ and $\left.y_{5}=y_{6}=y_{7}=0\right)$, the $2^{\text {nd }}$ $\left(y_{6}=y_{7}=0\right)$ and the $3^{\text {rd }}$ orders. Table I reports the parameters obtained for $P_{3}-P_{5}$. The $3 \mathrm{D}$ fitting according to the $3^{\text {rd }}$ order model is also illustrated in Fig. 4. These results show that the spatial non-linearity effect has relatively low impact. However, metrological applications that require a high degree of accuracy can benefit from a $3^{\text {rd }}$ order model that achieves a determination coefficient of nearly 1 computed on 259 points. Equivalent result has been found for $P_{6}-P_{4}$. The calibration has been also validated in the frequency band $55-75 \mathrm{GHz}$.

TABLE I. CALIBRATION COEFFICIENTS ESTABLISHED FOR $P_{3}-P_{5}-\mathrm{F}=60 \mathrm{GHz}$.

\begin{tabular}{|c|c|c|c|c|}
\hline Coefficient & Parameter & Order 1 & Order 2 & Order 3 \\
\hline$Y_{0}$ & 1 & -0.2457 & -0.2457 & -0.2457 \\
\hline$y_{1}$ & $\mathrm{I}$ & 0.6575 & 0.6592 & 0.6593 \\
\hline$y_{2}$ & $\mathrm{Q}$ & -1.1466 & -1.1466 & -1.1466 \\
\hline$y_{3}$ & $\mathrm{I}^{2}$ & \multirow{2}{*}{-0.0102} & -0.0504 & -0.0504 \\
\cline { 1 - 2 }$y_{4}$ & $\mathrm{Q}^{2}$ & & 0.0321 & 0.0321 \\
\hline$y_{5}$ & $\mathrm{IQ}$ & & -0.0152 & -0.0152 \\
\hline$y_{6}$ & $\mathrm{I}^{3}-3 \mathrm{I} \mathrm{Q}^{2}$ & & & -0.0001 \\
\hline$y_{7}$ & $\mathrm{Q}^{3}-3 \mathrm{I}^{2} \mathrm{Q}$ & & - & -0.0128 \\
\hline & & \multirow{2}{*}{$99.80 \%$} & $99.88 \%$ & $99.89 \%$ \\
\hline
\end{tabular}




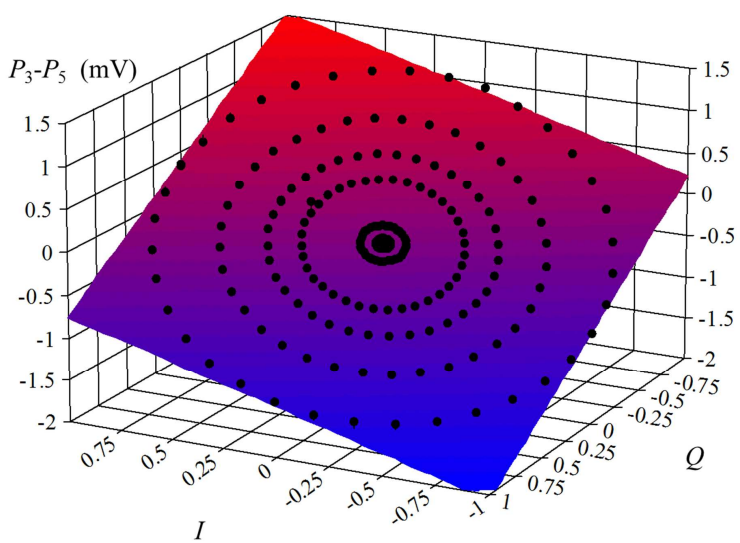

Fig. 4. IQ demodulation at $60 \mathrm{GHz}$ : 3D complex interpolation $\mathrm{F}=60 \mathrm{GHz} .(\bullet$ Measured data $)$.

\section{DisTANCE SENSING APPLICATIONS}

A distance measurement sensor based on the six-port demodulator associated to WR15 power divider, circulator and horn antenna is given in Fig. 5. The antenna with vertical polarization has been tested with stand-off $d$ from contact to $10 \mathrm{~mm}$ to a metallic target. For example, detected voltage $V_{1}$ as a function of $d$ shows the spread propagation losses that increase with $d$. Furthermore, resonances are related to wave recombination between the reflected wave by that target, the guided reflected wave at the antenna input (mismatch) and the free-space source match term (reflection of the received wave by the antenna). A dedicated free-space calibration method that takes into account these two effects can be implemented to derive the distance as a function of the measured voltages [10]. Complementary results will be shown in the last version of the paper.

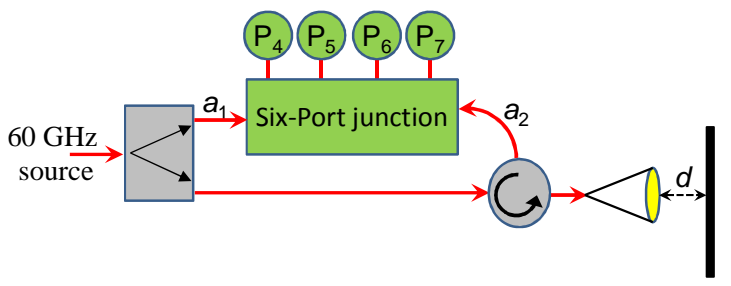

(a)

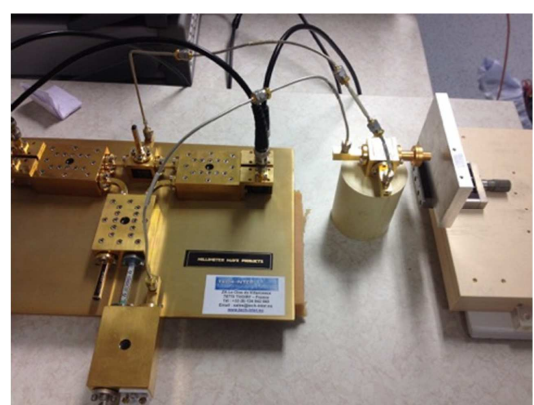

(b)

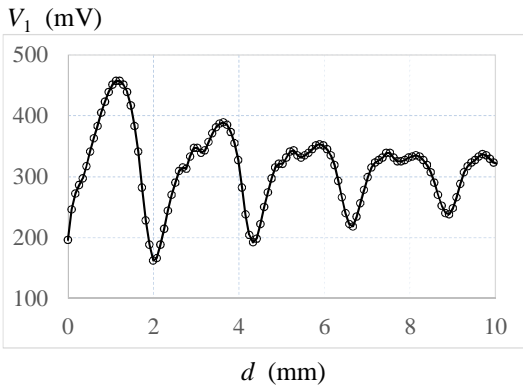

(c)

Fig. 5. Free-space distance measurement $-\mathrm{F}=60 \mathrm{GHz}$. (a) and (b) Experimental test bench. (c) Detected voltage $V_{1}$ as a function of the stand-off $d$.

\section{CONCLUSION}

A $60 \mathrm{GHz}$ six-port IQ demodulator in WR15 guide technology has been designed and tested. On this basis, a free-space six-port reflectometer has been described for close distance measurement in the $\mathrm{cm}$ range. Preliminary experiments show propagation of spherical waves combined with free-space stationary waves. Future work will provide all necessary calibration procedure for accurate extraction of distance and precision analysis.

\section{REFERENCES}

[1] G. Engen and C. Hoer, "Application of an arbitrary 6-port junction to power-measurement problems," IEEE Trans. Instrum. Meas., vol. 21, no. 4, pp. 470-474, Nov. 1972.

[2] J. Li, R. G. Bosisio, and K. Wu, "A collision avoidance radar using six-port phase/frequency discriminator," Proc. IEEE MTT-S Dig., pp. 1553-1555, May 1994.

[3] J. Osth, A. Serban, O. Owais, M. Karlsson, S. Gong, J. Haartsen, and P. Karlsson, "Six-port gigabit demodulator", IEEE Trans. Microw. Theory Tech., vol. 59, no. 1, pp. 125-131, January 2011.

[4] A. Koelpin, G. Vinci, B. Laemmle, D. Kissinger and R. Weigel, "The six-port in modern society," IEEE Microw. Mag., vol. 11, no. 7, pp. 35-43, Dec. 2010.

[5] A. Moscoso-Mártir, J.M. Ávila-Ruiz, E. Durán-Valdeiglesias, L. Moreno-Pozas, I. Molina-Fernández, A. Ortega-Moñux and J. deOliva-Rubio, "Butler matrix based six-port passive junction," IEEE WiSNet, pp.7-9, Jan. 2014.

[6] S. O. Tatu, A. Serban, M. Helaoui and A. Koelpin, "Multiport technology: the new rise of an old concept," IEEE Microw. Mag., vol. 15, no. 7, pp. 34-44, Nov. 2014.

[7] B. Laemmle, G. Vinci, L. Maurer, R. Weigel, and A. Koelpin, “A 77-GHz SiGe integrated six-port receiver front-end for angle-ofarrival detection," IEEE J. Solid-State Circuits, vol. 47, no. 9, pp. 1966-1973, Sept. 2012.

[8] A. Koelpin, F. Lurz, S. Linz, S. Mann, C. Will and S. Lindner, "Six-port based interferometry for precise radar and sensing applications", Sensors, vol. 16, no. 1556, pp. 1-26, Sept. 2016.

[9] K. Haddadi and T. Lasri, "Formulation for complete and accurate calibration of six-port reflectometers", IEEE Trans. Microw. Theory Tech., vol. 60, no. 3, pp. 574-581, March 2012.

[10] K. Haddadi, MM.Wang, O. Benzaim, D. Glay, and T. Lasri, "Contactless microwave technique based on a spread-loss model for dielectric materials characterization", IEEE Microw. Wireless Compon. Lett., vol. 19, no. 1, pp. 33-35, Jan. 2009. 